fatigue (Functional Assessment of Chronic Illness Therapy-Fatigue [FACIT-F] scale), \& 36-item Short Form Health Survey (SF-36) physical \& mental component summary (PCS \& MCS) scores \& weakly correlated with other variables (Figure 1). Based on univariate analyses $(p<0.20) \&$ evaluation of collinearity between variables, attributes at W0 \& W24 included in the multivariate models were age, sex, CRP, FACIT-F, pain, psoriasis area \& severity index (PASI) score, TJC, SJC, enthesitis, \& dactylitis. In the final model, CRP, FACIT-F, pain, PASI score, \& the presence of dactylitis were significantly associated with EQ-5D-5L index \& EQ-VAS scores. A higher TJC was significantly associated with a worse EQ-5D-5L index score. A higher SJC was significantly associated with a worse EQ-VAS score (Table 1). For reference, in the GUS Q4W ( $N=244)$, GUS Q8W $(\mathrm{N}=246)$, \& PBO $(\mathrm{N}=244)$ groups, the LS mean changes from baseline at W24 were $0.12,0.12$, \& 0.05 , respectively, for EQ-5D-5L index \& 18.1, 18.4, \& 6.8, respectively, for EQ-VAS

Conclusion: Joint \& skin symptoms, dactylitis, fatigue, pain, \& elevated levels of CRP were significantly associated with reduced HRQoL (measured by EQ-5D-5L index \& EQ-VAS) in bio-naïve pts with active PsA. Treatment of multiple PsA domains may help optimize HRQoL. Improvement across clinical domains ${ }^{1}$ \& in HRQoL has been observed in GUS-treated pts with PsA.

REFERENCES:

[1] Mease P, et al. Lancet 2020;395:1126-36.

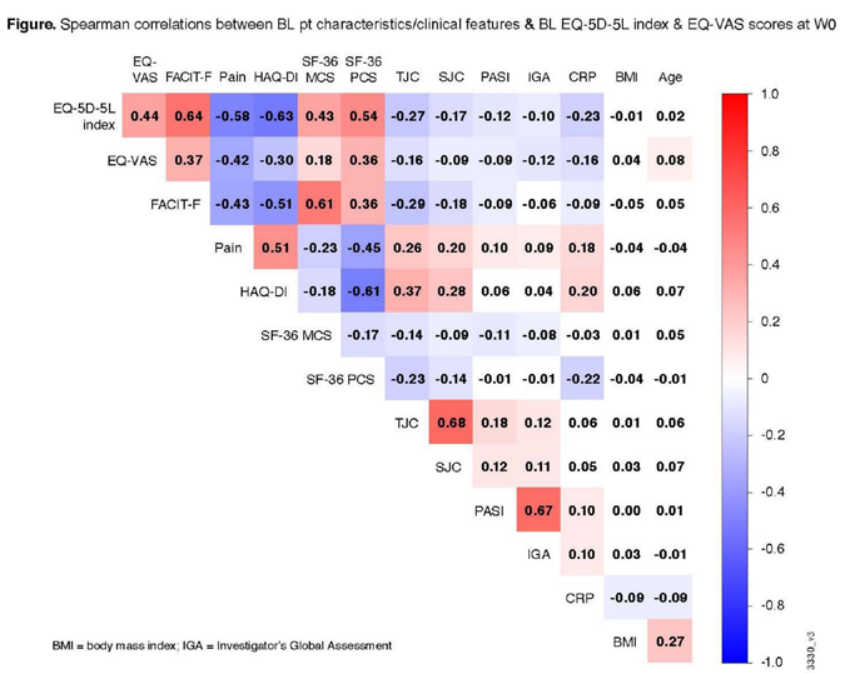

Table 1. Multivariate analysis of pt characteristics/clinical features \& EQ-5D-5L index \& EQ-VAS scores at W0 \& W24

\begin{tabular}{lcccc}
\hline Parameter & \multicolumn{2}{c}{ EQ-5D-5L Index } & \multicolumn{2}{c}{ EQ-VAS } \\
\hline & Estimate & p value & Estimate & p value \\
\hline Age (y) & -0.0001 & 0.69 & 0.06 & 0.12 \\
Female & -0.003 & 0.53 & 1.11 & 0.20 \\
CRP (mg/dL) & -0.005 & $<\mathbf{0 . 0 0 1}$ & -0.51 & $\mathbf{0 . 0 0 7}$ \\
FACIT-F (0-52) & 0.007 & $<\mathbf{0 . 0 0 1}$ & 0.57 & $<0.001$ \\
Pain (0-10) & -0.02 & $<0.001$ & -3.47 & $<0.001$ \\
PASI (0-72) & -0.001 & $\mathbf{0 . 0 3}$ & -0.17 & $<0.001$ \\
SJC (0-66) & -0.001 & 0.21 & -0.17 & $\mathbf{0 . 0 2}$ \\
TJC (0-68) & -0.001 & $\mathbf{0 . 0 4}$ & -0.04 & 0.41 \\
Dactylitis (Y/N) & 0.01 & $\mathbf{0 . 0 2}$ & 1.74 & 0.49 \\
Enthesitis (Y/N) & -0.004 & 0.33 & -0.98 & 0.22 \\
\hline
\end{tabular}

Disclosure of Interests: Jeffrey Curtis Consultant of: AbbVie, Amgen, Bristol-Myers Squibb, Corrona, Eli Lilly, Janssen, Myriad, Pfizer, Regeneron, Roche, and UCB, Grant/research support from: AbbVie, Amgen, Bristol-Myers Squibb, Corrona, Eli Lilly, Janssen, Myriad, Pfizer, Regeneron, Roche, and UCB, lain Mclnnes Consultant of: AbbVie, Bristol Myers Squibb, Celgene, Eli Lilly, Gilead, Janssen, Novartis, Pfizer, and UCB, Grant/research support from: Bristol Myers Squibb, Celgene, Eli Lilly, Janssen, and UCB, Dafna D Gladman Consultant of: Abbvie, Amgen, Bristol Myers Squibb, Eli Lilly, Galapagos, Gilead, Janssen, Novartis, Pfizer and UCB, Grant/research support from: Abbvie, Amgen, Bristol Myers Squibb, Eli Lilly, Galapagos, Gilead, Janssen, Novartis, Pfizer and UCB, Feifei Yang Shareholder of: Johnson \& Johnson, Employee of: Janssen Global Services, LLC, Steve Peterson Shareholder of: Johnson \& Johnson, Employee of: Janssen Global Services, LLC, Prasheen Agarwal Shareholder of: Johnson \& Johnson, Employee of: Janssen Research \& Development, LLC, Alexa Kollmeier Shareholder of: Johnson \& Johnson, Employee of: Janssen Research \& Development, LLC, Elizabeth C Hsia Shareholder of: Johnson \& Johnson, Employee of: Janssen Research \& Development, LLC, Chenglong Han Shareholder of: Johnson \& Johnson, Employee of: Janssen
Research \& Development, LLC, May Shawi Shareholder of: Johnson \& Johnson, Employee of: Janssen Global Services, LLC, William Tillett Speakers bureau: AbbVie, Amgen, Celgene, Eli Lilly, Janssen, Novartis, Pfizer, and UCB, Consultant of AbbVie, Amgen, Celgene, Eli Lilly, Janssen, Novartis, MSD, Pfizer, and UCB, Grant research support from: AbbVie, Celgene, Eli Lilly, Janssen, Novartis, Philip J Mease Consultant of: AbbVie, Amgen, Boehringer Ingelheim, Bristol Myers Squibb, Eli Lilly, Galapagos, Gilead, GlaxoSmithKline, Janssen, Novartis, Pfizer, SUN, and UCB Grant/research support from: AbbVie, Amgen, Bristol Myers Squibb, Eli Lilly, Galapagos, Gilead, Janssen, Novartis, Pfizer, SUN, and UCB, Proton Rahman Speakers bureau: AbbVie, Eli Lilly, Janssen, Novartis, Pfizer, and UCB, Consultant of: AbbVie, Amgen, Bristol Myers Squibb, Celgene, Eli Lilly, Janssen, Novartis, Pfizer, Roche, and UCB, Grant/research support from: Janssen and Novartis. DOI: 10.1136/annrheumdis-2021-eular.432

\section{POS1029 GUSELKUMAB-TREATED PATIENTS WITH PSORIATIC ARTHRITIS ACHIEVED CLINICALLY MEANINGFUL IMPROVEMENTS IN GENERAL HEALTH OUTCOMES MEASURED WITH PROMIS-29 THROUGH 52 WEEKS: RESULTS FROM THE PHASE 3 DISCOVER-1 TRIAL}

A. M. Orbai ${ }^{1}$, L. C. Coates $^{2}$, A. Deodhar ${ }^{3}$, P. Helliwell ${ }^{4}$, C. T. Ritchlin ${ }^{5}$,

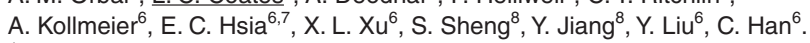
${ }^{1}$ Johns Hopkins University School of Medicine, Psoriatic Arthritis Program, Baltimore, United States of America; ${ }^{2}$ Oxford University, Nuffield Department of Orthopaedics, Rheumatology and Musculoskeletal Sciences, Oxford, United Kingdom; ${ }^{3}$ Oregon Health \& Science University, Division of Arthritis and Rheumatic Diseases, Portland, United States of America; ${ }^{4}$ University of Leeds, Leeds Institute of Rheumatic and Musculoskeletal Medicine, Leeds, United Kingdom; ${ }^{5}$ University of Rochester Medical Center, Department of Medicine, Allergy/lmmunology and Rheumatology, Rochester, United States of America; ${ }^{6}$ Janssen Research \& Development, LLC, Immunology, Spring House, United States of America; ${ }^{7}$ University of Pennsylvania School of Medicine, Rheumatology, Philadelphia, United States of America; ${ }^{8}$ Janssen Research \& Development, LLC, Biostatistics, Spring House, United States of America

Background: In the DISCOVER-1 study, the interleukin-23 p19 subunit inhibitor guselkumab (GUS) demonstrated robust efficacy across joint and skin clinical manifestations of psoriatic arthritis (PsA). ${ }^{1}$ Patients (pts) with PsA also experience a broad range of symptoms that negatively impact health-related quality of life (eg, pain, fatigue, anxiety, depression, sleep disturbance, poor physical function). ${ }^{2}$ Objectives: Assess the treatment effect of GUS on general health outcomes in pts with PsA in the DISCOVER-1 trial through Week (W) 52 using the Patient-Reported Outcomes Measurement Information System-29 (PROMIS-29) instrument. Methods: Pts with active PsA ( $\geq 3$ swollen $+\geq 3$ tender joints; C-reactive protein $\geq 0.3 \mathrm{mg} / \mathrm{dL}$ ) and inadequate response to standard conventional therapies were randomized 1:1:1 to GUS $100 \mathrm{mg}$ Q4W; GUS $100 \mathrm{mg}$ at W0, W4, then Q8W; or placebo (PBO). PBO pts switched to GUS $100 \mathrm{mg}$ Q4W at W24. PROMIS-29 contains 4 items for each of 7 domains (anxiety, depression, fatigue, pain interference, physical function, sleep disturbance, social participation) and 1 pain intensity item; 28 items are scored on a 5-point Likert-type scale, and pain intensity is rated from $0-10$. The raw score of each domain is converted to a standardized T-score, with norms based on a general population mean score $=50$ and a standard deviation $(S D)=10$. Higher scores in anxiety, depression, fatigue, pain interference, and sleep disturbance indicate more severe symptoms; higher physical function and social participation scores indicate better health outcomes. Changes $\geq 5$ points ( $1 / 2$ SD of T-score) are considered clinically meaningful. Analyses were performed using both observed (mean scores/changes, effect sizes) and imputed (clinically meaningful response, whereby change from baseline was set to 0 at W24/52 for pts who had missing data or at W24 for pts who met treatment failure criteria prior to W24)

Results: At baseline, mean PROMIS-29 T-scores for physical function, social participation, sleep disturbance, pain, and fatigue were worse in the 381 PsA pts enrolled in DISCOVER-1 than in the general US population. Across all 7 domains, observed mean PROMIS-29 T-scores showed improvements in GUS treated pts from baseline to W24 and W52 (Figure 1). Observed mean changes from baseline to W24 and W52, with calculated effect size, are shown (Table 1). In all pts, including those with imputed data, significantly higher percentages of pts in both GUS treatment groups vs PBO had $\geq 5$-point improvements in fatigue, pain interference, physical function, sleep disturbance, social participation, and pain intensity domains at W24 (all nominal $p<0.05$ ). Mean improvements in PROMIS-29 domains were maintained through W52.

Conclusion: In pts with active PsA, PROMIS-29 results indicate that GUS treatment was associated with clinically meaningful reductions in fatigue and pain and improvement in physical function and social participation, which were maintained through 1 year.

REFERENCES:

[1] Deodhar A et al. Lancet. 2020;395:1115-25.

[2] Orbai A et al. Ann Rheum Dis. 2017;76:673-80 
Figure. Mean PROMIS-29 T-scores at Baseline, W24, and W52 (Observed Data)

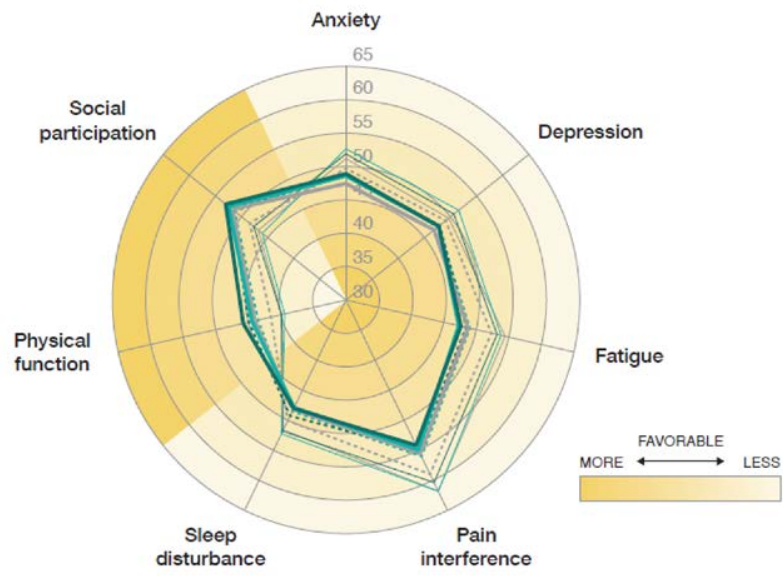

Baseline

Week 24

Week 52
GUS Q4W $(n=124)$

GUS Q8W ( $n=114)$ $\mathrm{PBO} \rightarrow \mathrm{GUS}$ Q4W $(\mathrm{n}=104)$

-Improvements are indicated by decreasing scores in anxiety, depression, tatigue, pain interference,

and sleep disturbance, and increasing scores in physical function and social participation.

Table 1. Mean Change and Effect Size of Change From Baseline in PROMIS-29 Domain Scores at W24 and W52 (Observed)

\begin{tabular}{|c|c|c|c|c|c|c|}
\hline & \multicolumn{6}{|c|}{ Mean Change From Baseline [Effect Size] } \\
\hline & \multicolumn{2}{|c|}{ GUS Q4W } & \multicolumn{2}{|c|}{ GUS Q8W } & \multirow{2}{*}{$\begin{array}{c}\begin{array}{c}\text { PBO } \\
\text { W0-24 }\end{array} \\
\text { W24 }\end{array}$} & \multirow{2}{*}{$\begin{array}{c}\text { GUS Q4W } \\
\text { W24-52 }\end{array}$} \\
\hline & W24 & W52 & W24 & W52 & & \\
\hline Anxiety & $-3.1[-0.3]$ & $-3.1[-0.3]$ & $-3.7[-0.4]$ & $-4.3[-0.5]$ & $-1.5[-0.2]$ & $-3.6[-0.4]$ \\
\hline Depression & $-2.7[-0.3]$ & $-3.0[-0.4]$ & $-4.0[-0.4]$ & $-4.0[-0.4]$ & $-0.6[-0.1]$ & $-2.5[-0.3]$ \\
\hline Fatigue & $-4.8[-0.5]$ & $-5.6[-0.6]$ & $-4.8[-0.5]$ & $-6.8[-0.7]$ & $-2.1[-0.2]$ & $-5.7[-0.6]$ \\
\hline Pain interference & $-5.4[-0.8]$ & $-6.2[-1.0]$ & $-5.8[-1.0]$ & $-7.0[-1.1]$ & $-2.8[-0.4]$ & $-6.3[-1.0]$ \\
\hline Physical function & $5.0[0.8]$ & $5.9[0.9]$ & $4.1[0.6]$ & $5.0[0.7]$ & $1.7[0.2]$ & $4.2[0.6]$ \\
\hline Sleep disturbance & $-2.5[-0.4]$ & $-3.9[-0.6]$ & $-3.8[-0.6]$ & $-4.4[-0.6]$ & $-1.5[-0.2]$ & $-3.3[-0.5]$ \\
\hline Social participation & $4.2[0.5]$ & $5.3[0.7]$ & $5.3[0.6]$ & $6.6[0.8]$ & $1.7[0.2]$ & $4.9[0.6]$ \\
\hline Pain intensity ${ }^{\star}$ & $-2.3[-1.2]$ & $-2.8[-1.5]$ & $-2.1[-1.1]$ & $-2.7[-1.4]$ & $-0.7[-0.4]$ & $-2.5[-1.3]$ \\
\hline
\end{tabular}

${ }^{*}$ Raw score; all other domains reported as T-score.

Disclosure of Interests: Ana-Maria Orbai Consultant of: Eli Lilly, Janssen, Novartis, Pfizer, UCB, Grant/research support from: Abbvie, Eli Lilly and Company, Celgene, Novartis, Janssen, Horizon, Laura C Coates Consultant of: AbbVie, Amgen, Biogen, Bristol Myers Squibb, Boehringer Ingelehim, Celgene, Domain, Eli Lilly, Gilead, Janssen, Medac, Novartis, Pfizer and UCB, Grant/ research support from: AbbVie, Amgen, Celgene, Eli Lilly, Gilead, Novartis, Pfizer, Atul Deodhar Speakers bureau: AbbVie, Eli Lilly, Janssen, Novartis, Pfizer, and UCB, Consultant of: AbbVie, Amgen, Boehringer Ingelheim, Bristol Myers Squibb, Celgene, Eli Lilly, Galapagos, GSK, Janssen, Novartis, Pfizer, and UCB, Grant/research support from: AbbVie, Eli Lilly, GSK, Novartis, Pfizer, and UCB, Philip Helliwell Consultant of: Galapagos, Janssen, and Novartis, Grant/research support from: Abbvie, Janssen, and Pfizer, Christopher T. Ritchlin Consultant of: AbbVie, Amgen, Gilead, Janssen, Lilly, Novartis, Pfizer, UCB Pharma, Grant/ research support from: AbbVie, Amgen, UCB Pharma, Alexa Kollmeier Shareholder of: Johnson \& Johnson, of which Janssen Research \& Development, LLC is a wholly owned subsidiary, Employee of: Janssen Research \& Development, LLC, Elizabeth C Hsia Shareholder of: Johnson \& Johnson, of which Janssen Research \& Development, LLC is a wholly owned subsidiary, Employee of: Janssen Research \& Development, LLC, Xie L Xu Shareholder of: Johnson \& Johnson, of which Janssen Research \& Development is a wholly owned subsidiary, Employee of: Janssen Research \& Development, LLC, Shihong Sheng Shareholder of: Johnson \& Johnson, of which Janssen Research \& Development, LLC is a wholly owned subsidiary, Employee of: Janssen Research \& Development, LLC, Yusang Jiang Employee of: Cytel, Inc., providing statistical support (funded by Janssen), Yan Liu Shareholder of: Johnson \& Johnson, of which Janssen Research \& Development, LLC is a wholly owned subsidiary, Employee of: Janssen Research \& Development, LLC, Chenglong Han Shareholder of: Johnson \& Johnson, of which Janssen Research \& Development, LLC is a wholly owned subsidiary, Employee of: Janssen Research \& Development, LLC. DOI: 10.1136/annrheumdis-2021-eular.471

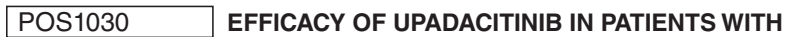 PSORIATIC ARTHRITIS STRATIFIED BY BASELINE SKIN SEVERITY: A SUBGROUP ANALYSIS OF TWO PHASE III TRIALS}

J. F. Merola ${ }^{1,2}$, P. Richette ${ }^{3}$, E. Lubrano ${ }^{4}$, E. Drescher ${ }^{5}$, L. Soto ${ }^{6}$, C. Lovan ${ }^{7}$, K. Kato ${ }^{7}$, R. Lippe ${ }^{8}$, M. Lane ${ }^{7}$, M. Kishimoto ${ }^{9} .{ }^{1}$ Brigham and Women's Hospital, Division of Rheumatology, Immunology and Allergy, Boston, United States of America; ${ }^{2}$ Harvard Medical School, Division of Rheumatology, Boston, United States of America; ${ }^{3}$ Hopital Lariboisiere Centre Viggo Petersen and Inserm UMR1132 Bioscar, Universite Paris Diderot UFR de Medecine, Service de Rhumatologie, Paris, France; ${ }^{4}$ University of Molise, Department of Medicine and Health Sciences Vincenzo Tiberio, Campobasso, Italy; ${ }^{5}$ Veszprém Csolnoky Ferenc County Hospital, Veszprém, Hungary; ${ }^{6}$ Universidad de Chile, Facultad de Medicina, Santiago, Chile; ${ }^{7}$ AbbVie, Immunology, North Chicago, United States of America; ${ }^{8} \mathrm{AbbVie}$ Deutschland GmbH \& Co. KG, Immunology, Wiesbaden, Germany; ${ }^{9}$ Kyorin University School of Medicine, Department of Nephrology and Rheumatology, Tokyo, Japan

Background: In the SELECT-PsA 1 and 2 clinical trials, upadacitinib (UPA) demonstrated efficacy and safety in patients (pts) with active psoriatic arthritis (PsA). ${ }^{1,2} \mathrm{PsA}$ is associated with varying degrees of psoriatic symptoms; however, the impact of skin severity on treatment outcomes is not well understood.

Objectives: This post-hoc analysis assessed the effects of baseline skin severity on UPA efficacy.

Methods: SELECT-PSA 1 and SELECT-PsA 2 enrolled pts with PsA and prior inadequate response (IR) or intolerance to $\geq 1$ non-biologic disease-modifying antirheumatic drug (DMARD) ${ }^{1}$ or $\geq 1$ biologic DMARD ${ }^{2}$, respectively. In both trials, pts received once daily UPA $15 \mathrm{mg}$ or UPA $30 \mathrm{mg}$ or placebo (switched at Wk 24 to either UPA $15 \mathrm{mg}$ or $30 \mathrm{mg}$ ); SELECT-PsA 1 also included the active comparator adalimumab (ADA). Only continuous UPA $15 \mathrm{mg}$ and ADA are presented here. In this analysis, pts were divided into subgroups based on the extent of psoriasis at baseline (body surface area $[\mathrm{BSA}]$ of $\geq 3 \%-<10 \%$ or BSA $\geq 10 \%$ ); efficacy endpoints were analyzed at Wk 56 . Results for binary endpoints are based on non-responder imputation; continuous endpoints are based on mixed model repeated measures analysis with as-observed data.

Results: In the UPA $15 \mathrm{mg}$ and ADA groups, respectively, 32\% (138/429) and $31 \%(132 / 429)$ of pts had a BSA $\geq 3-<10 \%$ at baseline in SELECT-PSA $1 ; 18 \%$ (76/429) in each treatment group had a BSA $\geq 10 \%$. In SELECT-PsA $2,38 \%$ (80/211) had a BSA $\geq 3-<10 \%$ and $24 \%(50 / 211)$ had a BSA $\geq 10 \%$ at baseline in the UPA $15 \mathrm{mg}$ group. Across pt populations (non-biologic DMARD-IR and biologic DMARD-IR), generally consistent results were observed between patients in both skin severity subgroups (Figure 1). In non-biologic DMARD-IR pts, a numerically greater proportion of UPA $15 \mathrm{mg}$ pts with lower skin involvement compared with higher skin involvement achieved PASI100 and PASI 1 , two more stringent

Figure. Efficacy Outcomes at Week $\mathbf{5 6}$ Stratified by the Severity of Skin Involvement at Baseline SELECT-PSA 1 - non-biologic DMARD-IR patients
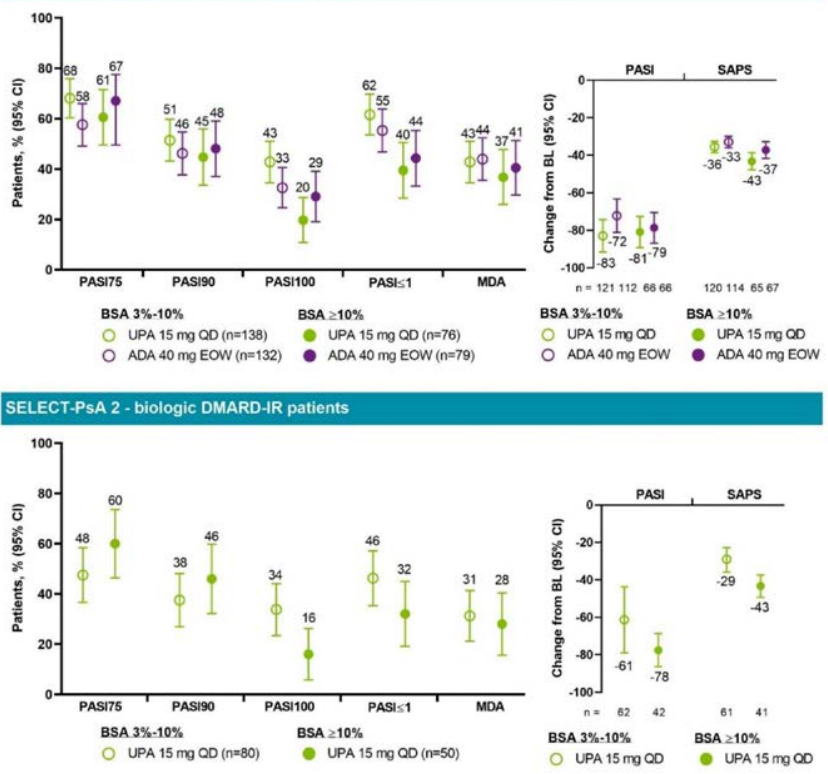

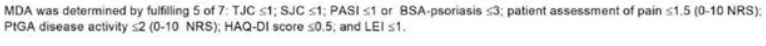
ADA, adalimumab; BL, baseline; BSA, body surtace area; CI, confdence interval; EOW, every other week; HAQ-DI, Health

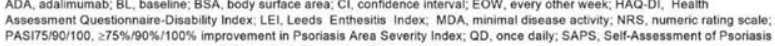

